\title{
Transcriptomic, proteomic, and physiological comparative analyses of flooding mitigating low temperature stress on direct-seeded early indica rice at seedling stage
}

\section{WENXIA WANG}

Jiangxi Agricultural University https://orcid.org/0000-0002-7680-7797

Jie Du

Jiangxi Agricultural University

Liming Chen

Jiangxi Agricultural University

Yongjun Zeng

Jiangxi Agricultural University

Xueming Tan

Jiangxi Agricultural University

Qinghua Shi

Jiangxi Agricultural University

Xiaohua Pan

Jiangxi Agricultural University

\section{Ziming Wu}

Jiangxi Agricultural University

Yanhua Zeng ( $\square$ zyh74049501@163.com )

https://orcid.org/0000-0002-1330-456X

Original article

Keywords: Low temperature, Flooding; proteomic, Transcriptomic, Physiological, Seedling stage

Posted Date: June 30th, 2020

DOI: https://doi.org/10.21203/rs.3.rs-38368/v1

License: (c) (1) This work is licensed under a Creative Commons Attribution 4.0 International License.

Read Full License 


\section{Abstract \\ Background}

Low temperature (LT) often occurs at seedling stage in early rice-growing season, especially for directseeded early-season indica rice seedlings, and adopting flooding irrigation could mitigate LT damage. However, it is not clear on the response mechanisms of a mitigating effect on LT stress at early rice seedling stage.

\section{Results}

In this study, LT stress with $10 / 6^{\circ} \mathrm{C}$ (day/night), LT accompanied by flooding (LTF) and CK (control) treatments were established for $3 \mathrm{~d}$ to aim to determine the response mechanisms on physiological, transcriptomic, and proteomic of direct-seeded rice seedlings at seedling stage. The results showed that the chloroplasts was severely degraded, thylakoid lamellae were seriously damaged and osmiophilic body increased gradually in LT contrast to CK, but LTF could alleviate the damage of low temperature on chloroplast structure. Compared with LT, LTF significantly increased the contents of Rubisco, chlorophyll, PEPCK, ATP and $\mathrm{GA}_{3}$ of rice seedlings whereas significantly decreased soluble protein, MDA and ABA content, suggesting the higher photosynthetic traits, antioxidant ability and better growth characteristic, although it could also affect the physiological activity contrast to CK. The identified differentially expressed genes and differentially expressed proteins indicated that photosynthesis metabolism pathway, reactive oxygen species and metabolic regulation had significant differences between LT and LTF stress, which were the main reasons that reduced the LT damage of rice seedlings for LTF.

\section{Conclusions}

Our results could provide comprehensive interpretation of physiological characteristics, genes and proteins expression changes in low temperature and low temperature flooding.

\section{Background}

Rice (Oryza sativa L.) is the staple food for more than half of the world's population (Khush. 2000). Given that the development of green revolution since the 1960s, rice yield has increased largely. As known as a typical thermophilic crop, the growth and development of rice are susceptibly affected by temperature, especially for low temperature (Sun et al. 2016). With the rise of global temperature and frequent occurrence of extreme weather, direct-seeded early indica rice often suffers from "Cold Spell in Later Spring" disaster at sowing and seedling stage. During the 30 years from 1951 to 1980, japonica and indica rice cultivars in the middle and lower reaches of the Yangtze River had encountered this disaster event for 7 times and 9 times, respectively, which resulted in a large area of rotten seeds and rotten seedlings of direct seeded rice, and seriously affected the production of direct seeded rice. In August 
2009, the Yanbian region of China was affected by continuous low temperature, resulting in the total crop failure for an area of $2310 \mathrm{hm}^{2}$ (Zhang et al. 2015). At the same time, although rice is a water-loving crop, the growth and development were also affected by long-term flooding stress, resulting in anaerobic respiration of roots and leaves, producing alcohol toxicity and reducing leaf photosynthesis. Therefore, it is particularly urgent to carry out indepth research on the response mechanism to low temperature stress of direct seeded early rice and its prevention measures to improve the high efficiency and stable yield of direct seeded rice.

In direct-seeded rice production, when the low temperature comes, farmers often reduce the damage of low temperature to seedlings by irrigating a certain amount of deep water layer, so as to achieve the role of protection seedling with deep water. Through this measure, the survival rate of seedlings emergence at seedling stage can be effectively increased and the production risk of direct-seeded rice can be reduced. To date, many studies have payed close attention to the points on rice cultivation, physiological traits, genetics mechanisms and other aspects injuries induced by low temperature stress (Zhang et al. 2012; Confalonieri et al. 2005; Zia et al. 2008) and flooding stress (Mishra et al. 2010; Lal et al. 2015). Previous studies on flooding mitigating low temperature stress mainly focus on agronomic traits or related physiological characteristics (Farrell et al. 2006). However, the molecular mechanism response on the seedlings damage of direct-seeded early indica rice to low temperature stress mitigating by flooding irrigation at seedling stage was rarely reported.

With the rapid development of biotechnology, an increasing number of studies about rice in response to different stress were profoundly analyzed by transcriptomic technologies (Cohen et al. 2017; Jithesh et al. 2018). The transcriptome analysis is fast and comprehensive, which has been constructed and annotated to assist in identification of differentially expressed genes (DEGs) in different plant populations (Vera et al. 2008). However, a comparison of mRNA expression levels is defined as indirect and temporarily messages in transmit information. On the contrary, proteins play a direct role in biological processes, and are the basis of organism (Marino et al. 2016). Protein is the embodiment and executor of plant functions, which not only regulates plant stress tolerance by changing the catalytic activity of enzymes, but also acts as a transcription factor to regulate the expression of other genes (Fu et al. 2019; Tse et al. 2013; Liang et al. 2013). Through the combination of transcriptome and proteome, many differentially expressed proteins (DEPs) have been identified and metabolic pathways have been found. On this basis, many differentially expressed genes related to metabolic pathways have been excavated, providing a molecular mechanism for finding responses to environmental stress.

At present, many studies have elucidated the influence mechanism of low temperature stress or flooding stress on rice seedlings from the aspects of proteomics and transcriptomics (Yang et al. 2015; Hussain et al. 2016). However, the mechanism of transcriptomics and proteomics based on low temperature flooding is still unclear. The molecular mechanism of the mitigative effect rather than superposition effect of the hypoxic treatment caused by flooding under low temperature is a scientific problem worthy of further study. This study combined transcriptomics and 4D-label free quantitative proteomics analysis to explore the molecular mechanism of flooding mitigating low temperature stress on direct-seeded early 
indica rice at seedling stage. Here, in this study, we identified genes and proteins that were obtained from Illumina-Hiseq and 4D-label free searching for likely protein identification in Gene Ontology (GO), Kyoto Encyclopedia of Genes and Genomes (KEGG), Klustersof eukaryotic Orthologous Groups (KOG), Swissport and Uniprot database, respectively, and focused on the DEGs and DEPs in flooding mitigating low temperature stress. This study has guiding significance to breeding and cultivation of low temperature tolerant crops cultivars. It also provides the evidence for the meteorological disaster mitigation and low temperature prevention.

\section{Result}

\section{Transmission electron microscopic observation of chloroplast structure}

In this study, transmission electron microscopy was used to analyze leaf phenotypic characteristics and compare the differences on chloroplasts structural of early indica rice seedlings after 3 days between LT and LTF. The results showed that chloroplasts were regular boat shaped or spindle shaped and thylakoid lamellae clear arranged close to the inner wall of cells in CK (Fig. 1C). Compared with CK, chloroplasts began to degrade, shaped distorted and loosely structured in LTF (Fig. 1B), however, chloroplasts had been severely degraded, thylakoid lamellae were seriously damaged and osmiophilic body increased gradually in LT (Fig. 1A). The damage to chloroplast structure in LTF was less than that in LT. These results showed that chloroplast were affected to some extent after low temperature stress, and flooding could alleviate low temperature damage on chloroplast structure.

\section{Analysis of photosynthesis activity andendogenous hormone content}

Rubisco is the key enzyme of photosynthetic carbon metabolism in $\mathrm{C}_{3}$ plants, which is positively correlated with the photosynthetic rate (Yu et al. 2012). Under LT stress, the balance of plant cell free radical production and elimination system is damaged, chlorophyll synthesis and energy metabolism are affected (Wang et al. 2006). This study showed that the rubisco content of LT was significantly decreased by $26.97 \%(P<0.05)$ compared to $\mathrm{CK}$, but there was no significant difference between LTF and CK (Fig. 2A). The PEPCK activity, chlorophyll content and ATP content of LT and LTF were significantly decreased $(P<0.05)$ compared with CK, and those indexs were lower in LT than in LTF (Fig. 2B; Fig. 2C; Fig. 2D). Endogenous hormones are signal molecules produced in the process of plant metabolism, which play an important role in plant growth and environmental response (Sakamoto T. 2006). Compared with $\mathrm{CK}$, the $\mathrm{GA}_{3}$ content of pro-growth hormones in LT and LTF decreased significantly (Fig. 2E). In contrast, the ABA content of anti-growth hormones in LT and LTF significantly increased by $35.71 \%$ and $16.67 \%(P<0.05)$, respectively (Fig. $2 \mathrm{~F})$. There were the same trends on $\mathrm{GA}_{3}$ and $A B A$ between $\mathrm{LT}$ and LTF, which reached a significant level. These results indicated that flooding could improve photosynthesis activity and endogenous hormone content under low temperature stress of direct-seeded early indica rice at seedling stage.

\section{Analysis of soluble protein content, antioxidase and osmotic regulatory substances}


Soluble protein is an important osmotic regulator that affects the osmotic potential of cells (Zhu et al. 2015). After plants were stressed, plant cell membrane would be damaged by free radicals and reactive oxygen species, resulting in membrane lipid peroxidation and protein activity affected (Vighi et al. 2017; Hu et al. 2017). This study showed that the content of soluble protein and MDA in LT and LTF increased significantly $(P<0.05)$ compared with $\mathrm{CK}$, and LT also significantly increased soluble protein and MDA contrast to LTF (Fig. 3A; Fig. 3B). In addition, LT and LTF significantly increased the activities of SOD and POD $(P<0.05)$ compared with $\mathrm{CK}$, and there were no significant differences between LT and LTF, although SOD and POD were higher in LT than in LTF (Fig. 3C; Fig. 3D).

\section{Identification of DEPs}

To evaluate the reliability of the data generated by proteomic analysis, the Pearson correlation coefficient was calculated for each of three samples, which indicated good reproducibility of the three biological replicates in each treatment (Fig. 4A). In addition, a total of 412489 spectrums were detected, 236880 of which could be matched to peptides in the database and 28934 were unique peptides. In total, 5639 proteins could be identified and 4518 proteins were experimentally quantified (Table 1 ).

Proteins with a fold change $(\mathrm{FC})>1.5$ or $(\mathrm{FC})<0.67(P<0.05)$ between the treatment $(\mathrm{LT}, \mathrm{LTF})$ and control groups (CK) were regarded as DEPs, and DEPs were hence considered as low temperature and low temperature flooding responsive proteins at the seedling stage. There were 567 DEPs between LT and CK, 239 DEPs between LTF and CK, and 235 DEPs between LTF and LT. The number of up-regulated and down-regulated DEPs was shown in Fig. 4B and the three groups had 16 DEPs in common (Fig. 4C).

In this study, 72818 transcripts and 5639 proteins were identified by quantitative transcriptome and proteome studies. 4983 genes were identified at both transcriptome and proteome levels (Fig. 4D). The correlation coefficient between transcripts and proteins in LT and CK treatment groups was 0.19 , that in LTF and CK treatment groups was 0.25 , and that in LT and LTF treatment groups was 0.22 . It indicates that the correlation degree of samples in each treatment group is low, and they are basically consistent with the expectation (Fig. 5).

\section{Gene functional description and $\mathrm{GO}$ analysis}

To annotate the function of low temperature flooding responsive proteins, the protein IDs were searched in the NCBI database (https:// www.ncbi.nlm.nih.gov/) and / or the UniProt database (http://www. uniprot.org/). For the DEPs between LT and CK, 197 up-regulated proteins and 369 down-regulated proteins showed annotated functions, and 1 down-regulated protein remained uncharacterized (Additional file 1: Dataset S1). For the DEPs between LTF and CK, both 114 up-regulated proteins and 125 down-regulated proteins could be annotated with functions (Additional file 2: Dataset S2). For the DEPs between LTF and LT, both 154 up-regulated proteins and 81 down-regulated proteins showed annotated functions (Additional file 3: Dataset S3). 
To determine the cellular component (CC), molecular function (MF) and biological process (BP) categories of GO for the low temperature and low temperature flooding response proteins, we searched their protein IDs against the GO database (Mi and Al. 2013). GO analysis showed that the DEPs were involved in fourteen subgroups of BP (Fig. 6A), ten subgroups of CC (Fig. 6B), and ten subgroups of MF (Fig. 6C) between LT and CK. The main biological process categories were metabolic process (30\%), cellular process $(25 \%)$, single-organism process $(18 \%)$, response to stimulus $(7 \%)$, localization $(7 \%)$, biological regulation (5\%), cellular component organization or biogenesis (4\%), other $(4 \%)$. The cellular component categories were cell (34\%), organelle (25\%), membrane (24\%), and macromolecular complex (12\%), other (5\%). The molecular function categories were binding (44\%), catalytic activity (42\%), transporter activity (5\%), structural molecule activity (4\%), and antioxidant activity (2\%), other (3\%) (Additional file 4: Figure S1).

GO analysis showed that the DEPs were involved in thirteen subgroups of BP (Fig. 6A), nine subgroups of CC (Fig. 6B), and ten subgroups of MF (Fig. 6C) between LTF and CK. The biological process categories were metabolic process $(30 \%)$, cellular process $(26 \%)$, single-organism process $(21 \%)$, and response to stimulus (7\%), biological regulation (5\%), cellular component organization or biogenesis (4\%), localization $(4 \%)$, other (3\%). The cellular component categories were cell (36\%), membrane (28\%), organelle (26\%), macromolecular complex (4\%), and extracellular region (3\%), other (3\%). The molecular function categories were catalytic activity (47\%), binding (44\%), structural molecule activity $(2 \%)$, and transporter activity (2\%), other (5\%) (Additional file 5: Figure S2).

GO analysis showed that the DEPs were involved in fourteen subgroups of BP (Fig. 6A), eight subgroups of CC (Fig. 6B), and nine subgroups of MF (Fig. 6C) between LTF and LT. The biological process categories were metabolic process $(27 \%)$, cellular process $(19 \%)$, single-organism process $(17 \%)$, localization (10\%), response to stimulus (7\%), biological regulation (5\%), developmental process (3\%), multicellular organismal process (3\%), cellular component organization or biogenesis (3\%), reproduction (3\%), other (5\%). The cellular component categories were membrane (33\%), cell $(29 \%)$, organelle $(23 \%)$, and macromolecular complex (12\%), other (3\%). The molecular function categories were binding (45\%), catalytic activity (41\%), transporter activity $(7 \%)$, and structural molecule activity $(3 \%)$, other (4\%) (Additional file 6: Figure S3).

\section{Protein-protein interaction}

The functional DEPs of all annotated were used to analyze protein interactions. This revealed that most enzymatic proteins and proteins related to biosynthesis of secondary metabolites, monobactam biosynthesis, metabolic pathways, pentose phosphate pathway, fructose and mannose metabolism, glycolysis / gluconeogenesis, glycine, serine and threonine metabolism, arachidonic acid metabolism, biosynthesis of amino acids, phenylalanine, tyrosine and tryptophan biosynthesis and proteasome related proteins interactions were affected by LT and CK (Additional file 7: Figure S4). Most enzymatic proteins and metabolic pathways, biosynthesis of secondary metabolites, carotenoid biosynthesis, ribosome biogenesis in eukaryotes, glycolysis/gluconeogenesis, glycine, serine and threonine metabolism 
photosynthesis and thiamine metabolism were observed for the interaction between LTF and CK (Additional file 8: Figure S5). Most enzymatic proteins and photosynthesis-antenna proteins, photosynthesis related proteins interactions were affected by LTF and LT (Additional file 9: Figure S6). In this study, the photosynthesis pathway and energy metabolism pathway were observed for being highly enriched under low temperature and low temperature flooding. This result showed that low temperature flooding played an important role in regulating the photosynthetic capacity of rice leaves. Consistent with our GO analysis findings, the majority of proteins were involved in photosynthesis and metabolic processes. We could focus on proteins related to photosynthesis and metabolism at the proteomic level.

\section{KEGG pathway analysis}

All of the DEGs and DEPs were analyzed for the KEGG over-representation of pathways to obtain functional insights into the difference between LT, LTF and CK treatment. The significantly $(P<0.01)$ enriched KEGG pathways are shown in Table 2. The KEGG pathways (ordered by rank) are monobactam biosynthesis, glycine, serine and threonine metabolism, biosynthesis of secondary metabolites, pentose phosphate pathway, biosynthesis of amino acids, metabolic pathways, arachidonic acid metabolism, glycolysis / gluconeogenesis, proteasome, phenylalanine, tyrosine and tryptophan biosynthesis, fructose and mannose metabolism between LT and CK. The KEGG pathways (ordered by rank) are thiamine metabolism, ribosome biogenesis in eukaryotes, carotenoid biosynthesis, biosynthesis of secondary metabolites, metabolic pathways, glycine, serine and threonine metabolism, glycolysis / gluconeogenesis between LTF and CK. The KEGG pathways (ordered by rank) are photosynthesis, photosynthesis antenna proteins between LTF and LT.

\section{Analysis of DEGs and DEPs by qRT-PCR}

To verify the proteomes and transcriptomes results, eighteen related genes including five up-regulated and thirteen down-regulated were detected. As shown that the mRNA expression of A2XLW5, B8AYU2, A2X822, B8ASV8 and A2XYC2 were down-regulated between LT and CK (Fig. 7A). The mRNA expression levels of A2YM28, A2XKN7, A2WRR8 and A2X8P7 were down-regulated between LTF and CK, B8AZB8, B8BJP8, B8AS16 were significantly up-regulated between LTF and CK (Fig. 7B). In LTF and LT, A2YMZ1, A2YCB9, A2YHC5 and A2YLE6 were down-regulated, and B8B7M5 and A2YP23 were up-regulated (Fig. 7C). Those as mentioned indicated that transcriptomes and proteomes results indeed reflected the relative expression of each gene, in which up-regulated or down-regulated genes in qRT-PCR were completely consistent with transcriptome and proteome trends. Therefore, the transcriptome results were reliable.

\section{Discussion}

\section{Photosynthesis response to flooding under low temperature stress}

Photosynthesis is one of the sensitive physiological and biochemical processes under low temperature (Winkel et al. 2014). After LT stress, the photosynthetic mechanism was damaged, electron transfer chain 
was interrupted and the stomatal conductance decreased (Qiu et al. 2017). In addition, LT not only affects the synthesis of chlorophyll in leaves, but also rapidly degrades chlorophyll and damages chloroplast cells (Yamori et al. 2014). In this study, transmission electron microscope observation showed that under LT stress, chloroplast and membrane lipids were seriously degraded, and osmiophilic granule were also numerous and large. LTF reduces the damage to chloroplast structure and protects seedlings through shallow flooding. LT affects the metabolism and physiology of crops, and has an indirect effect on leaf photosynthesis (Ayub et al. 2011; Nelson et al. 2006).

Rubisco is the key enzyme in photosynthesis that determines the carbon assimilation rate (Bowes et al. 2006). In this study, LTF could significantly increase the contents of rubisco and chlorophyll of rice seedlings compared with LT (Fig. 2A; Fig. 2B), and photosynthesis and glycine, serine and threonine metabolism were also significant enrichment between LT, LTF and CK (Table 2). The results of DEPs analysis indicated that phytochrome B (protein ID: A2XFW2) and phytochrome C (protein ID: A2XM23) were significantly down-regulated $(P<0.05)$ between $\mathrm{LT}$ and CK (Dataset 1$)$, and phytochrome $\mathrm{C}$ (protein ID: A2XM23), regulation of photosynthesis (protein ID: B8AWA3) were also significantly down-regulated $(P<0.05)$ between LTF and CK (Dataset 2). However, phytochrome B (protein ID: A2XFW2) and phytochrome $\mathrm{C}$ (protein ID: A2XM23) were significantly up-regulated $(P<0.05)$ between LTF and LT (Dataset 3), which supported the above results that LT could significantly inhibit the photosynthesis of rice leaf, and flooding could alleviate the effects. This was consistent with the results of previous studies (Makino et al., 2007; Liu et al., 2018). In addition, the DEPs also showed that chlorophyllide oxygenase activity (protein ID: A2XAH0, A2XCH9, A2XN43), and chloroplastic (protein ID: B8AD72) were significantly down-regulated $(P<0.05)$ between LT and CK (Additional file 1: Dataset S1), and chlorophyll proteins (protein ID: A2XIZ1, B8AM17) were significantly down-regulated $(P<0.05)$ between LTF and CK (Additional file 2: Dataset S2). On the contrary, chlorophyllide oxygenase activity (protein ID: A2XCH9) were significantly up-regulated $(P<0.05)$ between LTF and LT (Additional file 3: Dataset S3). The results showed that LT would lead to the degradation of pigment proteins in leaves, while LTF would improve a large amount of synthesis of pigment proteins in leaves, which was beneficial to the absorption of more solar energy in rice leaves and remission the effects of LT stress on photosynthesis.

\section{ROS response to flooding under low temperature stress}

When rice was subjected to LT stress, the balance of intracellular oxygen metabolism was disturbed, resulting in reactive oxygen species (ROS) production, aggravating membrane lipid peroxidation, producing MDA and damaging the cell membrane system (Sanghera et al. 2011). Soluble protein is an important osmotic regulator substance, and high concentration of soluble protein is helpful to improve plant stress resistance (Theocharis et al. 2012). The results of this study showed that the soluble protein content and MDA content in both LT and LTF were significantly increased contrast to CK. That further verified the above point of view. The accumulation of ROS might cause oxidative stress, but rice can regulate it through their antioxidant enzyme (such as POD and SOD) and non-enzymatic system (such as GSH) to resist the toxic effects of reactive oxygen free radicals under LT stress, reduce the damage of ROS accumulation to rice leaves and make it easier for rice to survive (Rosatellez et al. 2017; Xiong et al. 
2018). In this study, the activities of SOD and POD in LT and LTF were significantly increased contrast to CK (Fig. 3C; Fig. 3D). The results of DEPs analysis indicated that the antioxidant activity, response to stimulus, defense response and metabolic process were significantly enriched between LT and CK (Fig. 6). Here, the scavenging of the ROS related protein oxidase (protein ID: A2XX54, B8AKJ8), oxidoreductase (protein ID: A2YAP5) and glutathione peroxidase (protein ID: A2X822, B8ASV8) were significantly upregulated $(P<0.05)$ between LT and CK (Additional file 1: Dataset S1). Meanwhile, superoxide dismutase activity (protein ID: A2XAA0), oxidoreductase (protein ID: A2YAP5) and glutathione peroxidase (protein ID: B8ASV8) were significantly up-regulated $(P<0.05)$ between LTF and CK (Additional file 2: Dataset S2), although POD and SOD did not differ between LTF and LT. However, peroxidase (protein ID: B8ARU3) were significantly down-regulated between LTF and LT (Additional file 3: Dataset S3). These could show that the results of physiological and proteomic data were mutually verified. To survive under LT stress, rice plants activated their reactive oxygen scavenging system and reduced the damage caused by low temperature to rice seedling. However, because the temperature was too low and the damage of rice seedlings were serious, excessive ROS attacked rice, resulting in cell structure damage and metabolic disorder, which might be one of the crucial reasons for the damage of chloroplast structure. In this study, flooding plays a role in protecting seedlings from the direct stress of LT due to shallow flooding, which could improve the antioxidant enzyme protection system of direct seeded rice seedlings under LT.

\section{Metabolic regulation response to flooding under low temperature stress}

Under LT stress, the growth and development of rice involves the comprehensive regulation of many kinds of plant endogenous hormones, such as $A B A, G A_{3}$, etc., in which low temperature stress will cause a large amount of ABA accumulation (Nishiuchi et al. 2012). This study showed that compared with LTF, LT significantly increased the contents of ABA of rice seedlings and significantly decreased $\mathrm{GA}_{3}$ content, suggesting that flooding alleviated the damage of LT stress on the growth of rice plants. Energy metabolism is the material basis of normal growth, development and high yield of crops (Rhoades et al. 2005). PEPCK is important metabolic intermediate in glycolysis pathway that is the main rate-limiting enzymes and plays a key role in energy metabolism (Brigham et al. 2013; Bakszt et al. 2010). In this study, LTF could significantly increase the contents of ATP and PEPCK activity compared with LT (Fig. 2C; Fig. 2D), and KEGG pathway analysis indicated that biosynthesis of secondary metabolites, metabolic pathways, glycolysis / gluconeogenesis, glycine, serine and threonine metabolism were significantly enriched between LT, LTF and CK (Table 2). The results of DEPs analysis indicated that the glycolysis protein 6-phosphofructokinase (protein ID: B8BF81) and phosphoenolpyruvate carboxykinase (protein ID:A2XEP1) were significantly down-regulated $(P<0.05)$ between LT and CK (Additional file 1: Dataset S1), tricarboxylic acid cycle (protein ID: A2X2W9) and fructose 1,6-bisphosphate 1-phosphatase (protein ID: B8AYU2) were also significantly down-regulated between LTF and CK (Additional file 2: Dataset S2), which might be the key position to limit the glycolysis pathway, resulting in insufficient energy supply under LT at the seedling stage. However, galactosidase (protein ID: B8A982), pyruvate kinase (protein ID: B8ACJ0), glycoprotein glucosyltransferase (protein ID: B8AGC9), glucan branching enzyme (protein ID: B8ATS0) were significantly up-regulated $(P<0.05)$ between LTF and LT (Additional file 3: Dataset S3), 
and that could improve energy supply for the seedlings damage through flooding under LT stress. As a consequence, for low temperature stress, due to the disorder of energy metabolism, rice seedlings cannot be provided with the normal energy needed for growth and development, resulting in plant wilting.

\section{Conclusions}

The study provides novel insight into the physiological and molecular mechanisms of rice response to LT stress and LTF at seedling stage. The damage of chloroplast structure in rice leaves was alleviated by flooding under low temperature. LTF significantly increased the contents of rubisco, chlorophyll, PEPCK, ATP and $\mathrm{GA}_{3}$, and also enhanced photosynthesis and energy metabolism compared with LT. GO and KEGG enrichment analysis revealed that the DEPs were significantly associated with the photosynthesis pathway, metabolic regulation and reactive oxygen species. 4D-label-free quantitative proteomic and transcriptomic conjoint analysis showed that biosynthesis of secondary metabolites, metabolic pathways, glycolysis / gluconeogenesis, glycine, serine and threonine metabolism were significantly enriched under LT and LTF. Our results could provide comprehensive interpretation of physiological characteristics, genes and proteins expression changes in low temperature and low temperature flooding.

\section{Materials And Methods}

\section{Plant materials and growth conditions}

In this study, early indica rice cultivar Zhongjiazao 17 (ZJZ17) was selected for pot experiment, which is mainly generalized for rice production in Jiangxi Province. Zhongjiazao 17 bred by the China National Rice Research Institute (CNRRI) is the inbred indica rice. The pot experiment was conducted at the key laboratory of crop physiology of Jiangxi Agricultural University (JXAU) of Nanchang City, Jiangxi Province, China (longitude: $115^{\circ} 50 \otimes \mathrm{E}$; latitude: $28^{\circ} 46 \otimes \mathrm{N}$ ). Rice was planted in plastic pots with $15.0 \mathrm{~cm}$ height, $25.0 \mathrm{~cm}$ length and $23.0 \mathrm{~cm}$ wide. Soil samples of the plastic pots were derived from the upper soil layer $(0-20 \mathrm{~cm})$ of the rice experiment paddy field at the experimental site located at the science and technology park of JXAU. The soil fertility properties were as the following: soil organic matter $30.35 \mathrm{~g} \cdot \mathrm{kg}^{-}$

${ }^{1}$, total nitrogen (N) $2.4 \mathrm{~g} \cdot \mathrm{kg}^{-1}$, available phosphorus $(\mathrm{P}) 25.17 \mathrm{mg} \cdot \mathrm{kg}^{-1}$, available potassium (K) 84.02 $\mathrm{mg} \cdot \mathrm{kg}^{-1}$, and $\mathrm{pH}$ 6.1. The soil was naturally blown-dried, crushed by a soil grinder (FT-1000A, Changzhou WIK Instrument Manufacturing Co. Ltd., China), and then sifted by a 100-mm mesh. Each pot filled approximately six kilograms of dry soil that was soaked in water for two weeks before direct seeding. $3 \mathrm{~g}$ compound fertilizer (N-P-K $=15-15-15 \%)$ was applied as base fertilizer 1 day before direct seeding. Other management measures were in accordance with local recommendations.

\section{Experimental design}

Germinated seeds were selected for direct seeding, then all pots were placed in artificial climate chamber with a diurnal temperature of $27 / 23^{\circ} \mathrm{C}$ (day/night). After 20 days of direct seeded, one-third pots of rice seedlings with three leaves continued to be kept in suitable temperature artificial climate chamber 
$27 / 23^{\circ} \mathrm{C}$ (day/night) as control (CK), and the two-thirds pots of rice seedlings were equally moved to another artificial climate chamber for low temperature (LT) and low temperature flooding (LTF) treatment. For low temperature (LT), the diurnal temperature was set $10 / 6^{\circ} \mathrm{C}$ (day/night), and the period of low temperature treatment was 3 days that the light intensity was $100 \mathrm{mmol} \cdot \mathrm{m}^{-2} \mathrm{~s}^{-1}$ and the relative humidity $(\mathrm{RH})$ of the artificial climate chamber was $75 \%$, and potting soil remained moist. During the treatment, the positions of each pot were rotated from time to time to avoid the influence of light on seedling growth. For low temperature flooding treatment (LTF), temperature and treatment period were both the same as LT treatment, and the rice plants were maintained in a 5-6 cm flood water layer. For control (CK), rice seedlings were grown in artificial climate chamber that the diurnal temperature was $27 / 23^{\circ} \mathrm{C}$ (day/night), keep the soil moist. Each treatment was consisted of three replicates, and 20 pots constituted each replication.

\section{Transmission electron microscopic observation}

After 3 days of low temperature and low temperature flooding, the middle and upper parts of the leaves were cut into $1 \times 1 \mathrm{~cm}$ long with a blade, and immediately put into the $2.5 \%$ glutaric dialdehyde fixative, vacuumized until the sample was completely submerged, and then they were fixed overnight at $4^{\circ} \mathrm{C}$, taken about 10 pieces for each sample. The sample processing methods were according to the method of Huang et al (2018).

\section{Physiological and biochemical characteristic}

Enzymatic activity and endogenous hormones contents were measured on the third days of low temperature and low temperature flooding treatment. In each replicate experiment, three pots of plants were selected for each treatment group, $3 \mathrm{~g}$ leaf sample was collected and immediately frozen in liquid $\mathrm{N}_{2}$ and stored at $-80^{\circ} \mathrm{C}$ until extraction. PEPCK activity and Rubisco, chlorophyll, ATP, ABA, GA 3 content (Song et al. 2018; Qin et al. 2018; Feng et al. 2017; Teng et al. 2017; Bai et al. 2018) were measured using their assay kits respectively, according to the manufacturer's instruction (Cominbio, Suzhou, China). Soluble protein content, peroxidase (POD) activity, superoxide dismutase (SOD) activity and malondialdehyde (MDA) content were determined by configuration of solution (Campion et al. 2011; Garcia-Triana et al. 2010; Castrejon and Yatsimirsky 1997).

\section{RNA isolation, library preparation, and sequencing}

According to the RNA extraction scheme, the total RNA was separated by Trizol reagent (Invitrogen, Waltham, MA, USA). RNA purity was checked by the Nano Photometer ${ }^{\circledR}$ spectrophotometer (IMPLEN, CA, USA). And the integrity of the RNA was assessed by the RNA Nano 6000 Assay Kit of the Bioanalyzer 2100 system (Agilent Technologies, CA, USA). The quality and quantity of the RNA samples were determined by Nanodrop 2000 spectrophotometer (Thermo, USA).

The total amount of $3 \mu \mathrm{g}$ RNA per sample was used as the input material for RNA sample preparation. Sequencing libraries were generated using NEBNext ${ }^{\circledR}$ Ultra ${ }^{T M}$ RNA Library Prep Kit for Illumina ${ }^{\circledR}$ (NEB, 
USA) following manufacturer's recommendations and index codes were added to attribute sequences to each sample. Briefly, mRNA was purified from total RNA using poly-Toligo-attached magnetic beads. Fragmentation was carried out using divalent cations under elevated temperature in NEBNext First Strand Synthesis Reaction Buffer (5X). First strand cDNA was synthesized using random hexamer primer and MMuLV Reverse Transcriptase (RNase H-). Second strand cDNA synthesis was subsequently performed using DNA polymerase I and RNase H. Remaining overhangs were converted into blunt ends via exonuclease/polymerase activities. After adenylation of 3' ends of DNA fragments, NEBNext Adaptor with hairpin loop structure were ligated to prepare for hybridization. In order to select CDNA fragments of preferentially 150 200 bp in length, the library fragments were purified with AMPure XP system (Beckman Coulter, Beverly, USA). Then $3 \mu$ L USER Enzyme (NEB, USA) was used with size- selected, adaptor-ligated cDNA at $37^{\circ} \mathrm{C}$ for $15 \mathrm{~min}$ followed by 5 minat $95^{\circ} \mathrm{C}$ before PCR. Then PCR was performed with Phusion High-Fidelity DNA polymerase, Universal PCR primers and Index (X) Primer. At last, PCR products were purified (AMPure XP system) and library quality was assessed on the Agilent Bioanalyzer 2100 system. Then the library preparation was sequenced on Illumina Hiseq 2500/X platform and $125 / 150$ bp paired end reads were generated. RSEM (version 1.2.15) was used to quantify the mRNA abundance.

\section{Differential expression analysis for RNA-seq data}

Expected number of Fragments per Kilobase of transcript per Million fragments mapped (FPKM) values were obtained using Cufflink software (version 2.1.1), which was used as values for normalized gene expression. Differential expression analyses of two comparison groups were performed using the DESeq $R$ package (1.10.1). DESeq provide statistical routines for determining differential expression in digital gene expression data using a model based on the beta negative binomial distribution. The resulting $P$ values were corrected by the Benjamini-Hochberg method. Genes with an adjusted $P$-value $<0.01$ and fold change $>2$ found by DESeq were assigned as differentially expressed.

\section{Protein extraction, trypsin digestion and TMT labeling}

The sample was first grinded by liquid nitrogen, and then the powder was transferred to a $5 \mathrm{~mL}$ centrifuge tube. After that, four volumes of lysis buffer (8 M urea, 1\% Protease Inhibitor Cocktail) were added to the cell powder, followed by sonication three times on ice using a high intensity ultrasonic processor (Scientz, China). The samples were centrifuged at $12,000 \times \mathrm{g}$ at $4^{\circ} \mathrm{C}$ for $10 \mathrm{~min}$ and the debris was removed. Finally, the protein concentration was determined with BCA kit (Beyotime, China) according to the manufacturer's instructions.

For digestion, the protein solution was reduced with $5 \mathrm{mM}$ dithiothreitol for $30 \mathrm{~min}$ at $56^{\circ} \mathrm{C}$ and alkylated with $11 \mathrm{mM}$ iodoacetamide for $15 \mathrm{~min}$ at room temperature in darkness. The protein sample was then diluted by adding $100 \mathrm{mM}$ TEAB to urea concentration less than 2M. Finally, trypsin was added at 1: 50 trypsin-to-protein mass ratio for the first digestion overnight and 1: 100 trypsin-to-protein mass ratio for a second 4 h-digestion. 
After trypsin digestion, peptide was desalted by Strata X C18 SPE column (Phenomenex, USA) and vacuum-dried. Peptide was reconstituted in 0.5M TEAB and processed according to the manufacturer's protocol for TMT kit. The peptide mixtures were then incubated for $2 \mathrm{~h}$ at room temperature and pooled, desalted and dried by vacuum centrifugation.

\section{LC-MS/MS analysis and database search}

The tryptic peptides were dissolved in $0.1 \%$ formic acid (solvent $A$ ), directly loaded onto a home-made reversed-phase analytical column ( $15 \mathrm{~cm}$ length, $75 \mu \mathrm{m}$ i.d.). The gradient was comprised of an increase from $6 \%$ to $23 \%$ solvent B ( $0.1 \%$ formic acid in $98 \%$ acetonitrile) over $26 \mathrm{~min}, 23 \%-35 \%$ in 8 min and climbing to $80 \%$ in $3 \mathrm{~min}$ then holding at $80 \%$ for the last $3 \mathrm{~min}$, all at a constant flow rate of $400 \mathrm{~nL} / \mathrm{min}$ on an EASY-nLC 1000 UPLC system (Thermo, Waltham, USA).

The peptides were subjected to NSI source followed by tandem mass spectrometry (MS/MS) in Q ExactiveTM Plus (Thermo) coupled online to the UPLC. The electrospray voltage applied was $2.0 \mathrm{kV}$. The $\mathrm{m} / \mathrm{z}$ scan range was 350 to 1.800 for full scan, and intact peptides were detected in the Orbitrap at a resolution of 70,000. Peptides were then selected for MS/MS using NCE setting as 28 and the fragments were detected in the Orbitrap at a resolution of 17,500. A data-dependent procedure that alternated between one MS scan followed by $20 \mathrm{MS} / \mathrm{MS}$ scans with 15.0 s dynamic exclusion. Automatic gain control (AGC) was set at 5E4. Fixed first mass was set as $100 \mathrm{~m} / \mathrm{z}$.

The resulting MS/MS data were processed using Maxquant search engine (v.1.5.2.8). Tandem mass spectra were searched against human uniprot database concatenated with reverse decoy database. Trypsin/P was specified as cleavage enzyme allowing up to 4 missing cleavages. The mass tolerance for precursor ions was set as $20 \mathrm{ppm}$ in First search and $5 \mathrm{ppm}$ in main search, and the mass tolerance for fragment ions was set as $0.02 \mathrm{Da}$. Carbamidomethyl on Cys was specified as fixed modification and acetylation modification and oxidation on Met were specified as variable modifications. FDR was adjusted to $<1 \%$ and minimum score for modified peptides was set $>40$.

\section{Confirmation using qRT-PCR}

To verify the accuracy of transcriptome and proteome results, eighteen DEGs involved in LT, LTF and CK responses were selected for verification using qRT-PCR. The RNA used for qRT-PCR was the same with those used to construct cDNA library. The primers were designed using Primer 5.0 (Additional file 10: Table S1) and synthesized by Xiamen Life-Int Technology Co., Ltd and 18s (GenBank Accession NO. AK059783) acted as the reference gene.

\section{Statistical Analysis}

The data were analyzed by analysis of variance (SAS Institute Inc., Cary, NC), and the means of different treatments were examined by Tukey's honest significant difference (HSD) test to compare the differences at the probability level of 0.05 . 


\section{Abbreviations}

CK: control; LT:low temperature; LTF:low temperature flooding; DEPs:differentially expressed proteins; DEGs:differentially expressed genes; LC-MS:liquid chromatograph- mass spectrometry; GO:gene ontology; KEGG:kyoto encyclopedia of genes and genomes; KOG:klustersof eukaryotic orthologous groups; FC:fold change; BP:biological process; CC:cellular component; MF:molecular function; RH:relative humidity; Rubisco:ribulose bisphosphate carboxylase oxygenase; POD:peroxidase; SOD:superoxide dismutase; MDA:malondialdehyde; PEPCK:phosphoenolpyruvate carboxykinase; $\mathrm{GA}_{3}$ :gibberellin $\mathrm{A}_{3}$; $\mathrm{ABA}$ :abscisic acid; FW:fresh weight; HSD:honst significant difference.

\section{Declarations}

\section{Availability of data and materials}

All data generated or analyzed during this study are included in this published article and its additional files.

\section{Ethics approval and consent to participate}

Not applicable.

\section{Consent for publication}

Not applicable.

\section{Competing interests}

The authors declare that they have no competing interests.

\section{Funding}

This work was supported by the National Natural Science Foundation of China (Grant No: 31760366), the National Key Research and Development Program (Grant No: 2016YFD0300501 and 2017YFND0301605), and Jiangxi Natural Science Foundation of China (Grant No: 20161BAB214171).

\section{Authors' contributions}

Zeng Yanhua conceived and designed the experiments. Du Jie and Chen Liming conducted experiments and analyzed the data. Wu Ziming, Zeng Yongjun, Tan Xueming, Shi Qinghua, Pan Xiaohua contributed 
reagents/materials/analysis tools. Wang Wenxia wrote the manuscript. All authors read and approved the manuscript.

\section{Acknowledgements}

We thank the workers who have been at the forefront of the fight against the COVID-19 pandemic, allowing us to focus on writing this paper.

\section{References}

1. Ayub G, Smith RA, Tissue T, Atkin OK (2011) Impacts of drought on leaf respiration in darkness and light in Eucalyptus exposed to industrial-age atmospheric $\mathrm{CO}_{2}$ and growth temperature. New Phytol 190:1003-1018

2. Bahr BL, Stevens J, Squire S, Moreno C, Call LT, Stephens B, Bearss DJ (2013) Abstract 1875: A novel series of metabolic activators of PKM2 alter oncogene-meditated changes in tumor cell metabolism. Can Res 73:1875-1875

3. Bai LQ, Liu YM, Mu Y, Anwar A, He CX, Yan Y, Li YS, Yu XC (2018) Heterotrimeric G-protein y subunit CsGG 3.2 positively regulates the expression of $\mathrm{CBF}$ genes and chilling tolerance in cucumber. Front Plant Sci 9:488

4. Bakszt R, Wernimont A, Allalihassani A, Mok MW, Hills T, Hui R, Pizarro JC (2010) The crystal structure of toxoplasma gondii pyruvate kinase 1. Plos One 5:e12736

5. Bowes $\mathrm{G}$ (2006) Growth at elevated $\mathrm{CO}_{2}$ : photosynthetic responses mediated through rubisco. Plant Cell Environment 14:795-806

6. Campion EM, Loughran ST, Walls D (2011) Protein quantitation and analysis of purity. Methods Mol Biol 681:229-258

7. Castrejon SE, Yatsimirsky AK (1997) Cyclodextrin enhanced fluorimetric determination of malonaldehyde by the thiobarbituric acid method. Talanta 44:951-957

8. Cohen SP, Liu HX, Argueso CT, Pereira A, Cruz CC, Verdier V, Leach JE (2017) RNA-Seq analysis reveals insight into enhanced rice Xa7-mediated bacterial blight resistance at high temperature. Plos One 12:e0187625

9. Confalonieri R, Mariani L, Bocchi S (2005) Analysis and modelling of water and near water temperatures in flooded rice (oryza sativa L). Ecol Model 183:269-280

10. Farrell TC, Fox KM, Williams RL, Fukai S (2006) Genotypic variation for cold tolerance during reproductive develop ment in rice: screening with cold air and cold water. Field Crops Res 98:178194

11. Feng B, Huang X, Jiang D, Hua L, Zhuo Y, Wu D (2017) Endoplasmic Reticulum Stress Inducer Tunicamycin Alters Hepatic Energy Homeostasis in Mice. Int J Mol Sci 18:1710 
12. Fu SL, Ding MM, Liang QJ, Yang YJ, Chen M, Wei XF, Wang AL, Liao SA, Ye JM (2019) The key differentially expressed genes and proteins related to immune response in the spleen of pufferfish (Takifugu obscurus) infected by Aeromonas hydrophila. Fish Shellfish Immunology 91:1-11

13. Garcia-Triana A, Zenteno-Savin T, Peregrino-Uriarte AB, Yepiz-Plascencia G (2010) Hypoxia, reoxygenation and cytosolic manganese superoxide dismutase (cMnSOD) silencing in Litopenaeus vannamei: effects on cMnSOD transcripts, superoxide dismutase activity and superoxide anion production capacity. Dev Comp Immunol 34:1230-1235

14. Hu N, Tu. XR, Li KT, Liu YK, Guo A, Tu GQ, Huang L (2017) Changes in antioxidant enzyme activities and malondialdehyde (MDA) content of rice with blast resistance induced by Ag-antibiotic 702. Plant Diseases Pests 2:36-40

15. Huang JL, Lun X, Liu CH (2018) Transmission electron microscopic sample preparation method for rice leaf. Journal of Chinese Electron Microscopy Society 37:386-389

16. Hussain S, Yin HQ, Peng SB, Khan FA, Khan F, Sameeullah M, Hussain HA, Huang JL, Cui KH, Nie LX (2016) Comparative Transcriptional Profiling of Primed and Non-primed Rice Seedlings under Submergence Stress. Front Plant Sci 7:1125

17. Jithesh MN, Shukla PS, Kant P, Joshi J, Critchley AT, Prithiviraj B (2019) Physiological and transcriptomics analyses reveal that ascophyllum nodosum extracts induce salinity tolerance in arabidopsis by regulating the expression of stress responsive genes. J Plant Growth Regul 38:463478

18. Khush GS (2000) Strategies for increasing the yield potential of rice. Studies in Plant Science 7:207212

19. Lal B, Gautam P, Mohanty SR, Raja R, Tripathi R, Shahid M, Nayak AK (2015) Combined application of silica and nitrogen alleviates the damage of flooding stress in rice. Crop Pasture science 66:679688

20. Liang C, Tian J, Liao H (2013) Proteomics dissection of plant responses to mineral nutrient deficiency. Proteomics 13:624-636

21. Liu J, Yin XH, Gu AM, Cheng WW, Ye ZW, Zhou MY (2018) Affects of waterlogging stress on growth traits and yield of rice at tillering stage. Journal of Water Resources Architectural Engineering $16: 225-229$

22. Makino A, Sage RF (2007) Temperature response of photosynthesis in transgenic rice transformed with'Sense' or 'Antisense' rbcS. Plant Cell Physiol 48:1472-1483

23. Marino D, Ariz I, Lasa B, Santamaria E, Fernandez-Irigoyen J, Gonzalez-Murua C (2016) Quantitative proteomics reveals the importance of $\mathrm{N}$ source to control glucosinolate metabolism in Arabidopsis thaliana and Brassica oleracea. J Exp Bot 67:3313-3323

24. Mi H, Muruganujan A, Casagrande JT, Thomas PD (2013) Large-scale gene function analysis with the panther classification system. Nat Protoc 8:1551-1566

25. Mishra A, Salokhe VM (2010) Flooding stress: the effects of planting pattern and water regime on root morphology, physiology and grain yield of rice. Journal of Agronomy Crop Science 196:368-378 
26. Nelson N, Yocum CF (2006) Structure and function of photosystems I and II. Annu Rev Plant Biol 57:521-565

27. Nishiuchi S, Yamauchi T, Takahashi H, Kotula L, Nakazono M (2012) Mechanisms for coping with submergence and waterlogging in rice. Rice 5:2-2

28. Qin $L Y$, Xue YX, Fei Y, Zeng LF, Yang SS, Deng XP (2018) Identification, evolution and expression analyses of ribulose-1,5-bisphosphate carboxylase/oxygenase small subunit gene family in wheat (triticum aestivum I.). Acta Physiol Plant 40:85

29. Qiu CP, Ethier G, Pepin S, Dube P, Desjardins Y, Gosselin A (2017) Persistent negative temperature response of mesophyll conductance in red raspberry (Rubus idaeus L.) leaves under both high and low vapour pressure deficits: a role for abscisic acid? Plant. Cell Environment 40:1940-1959

30. Rhoades RD, King DA, Jenschke BE, Behrends JM, Hively TS, Smith SB (2005) Postmortem regulation of glycolysis by 6-phosphofructokinase in bovine msternocephalicus pars mandibularis. Meat Sci 70:621-626

31. Rosatellez S, Anoman AD, Florestornero M, Toujani W, Alseekh S, Fernie AR, Ros R (2017) Phosphoglycerate Kinases Are Co-Regulated to Adjust Metabolism and to Optimize Growth. Plant Physiol 176:1182-1198

32. Sakamoto T (2006) Phytohormones and rice crop yield:strategies andopportunities for genetic improvemen. Transgenic Res 15:399-404

33. Sanghera GS, Wani SH, Hussain W. Singh NB (2011) Engineering cold stress tolerance in crop plants. Curr Genomics 12:30-43

34. Song HS, Seo HM, Jeon JM, Moon YM, Hong JW, Hong YG, Bhatia SK, Ahn J, Lee H, Kim W, Park YC, Choi KY, Kim YG, Yang YH (2018) Enhanced isobutanol production from acetate by combinatorial overexpression of acetyl-CoA synthetase and anaplerotic enzymes in engineered Escherichia coli. Biotechnol Bioeng 115:1971-1978

35. Sun ZY, Wang XF, Yamamoto H, Zhang JQ, Tani H, Zhong GS, Yin S (2016) Extraction of rice-planting area and identification of chilling damage by remote sensing technology: a case study of the emerging rice production region in high latitude. Paddy Water Environ 15:181-191

36. Teng YB, Cui HQ, Wang MY, Liu XY (2017) Nitrate reductase is regulated by circadian clockassociated 1 in arabidopsis thaliana. Plant Soil 416:477-485

37. Theocharis A, Clement C, Barka EA (2012) Physiological and molecular changes in plants grown at low temperatures. Planta 235:1091-1105

38. Tse WK, Sun J, Zhang H, Law AY, Yeung BH, Chow SC (2013) Transcriptomic and iTRAQ proteomic approaches reveal novel short-term hyperosmotic stress responsive proteins in the gill of the Japanese eel (Anguilla japonica). J Proteom 89:81-94

39. Vera JC, Wheat CW, Fescemyer HW, Frilander MJ, Crawford DL, Hanski I, Marden JH (2008) Rapid transcriptome characterization for a nonmodel organism using 454 pyrosequencing. Mol Ecol $17: 1636-1647$ 
40. Vighi IL, Benitez LC, Amaral MN, Moraes GP, Auler PA, Rodrigues GS, Braga EJB (2017) Functional characterization of the antioxidant enzymes in rice plants exposed to salinity stress. Biol Plant 61:540-550

41. Wang P, Zhang CJ, Chen GX, Wang J, Shi DW, Lu CG, Zuo M, Liu RR (2006) Effects of low temperature on fatty acid composition of thylakoid membranes and lipid peroxidation in leaves of rice seedlings. Chinese Journal of Rice Science 20:401-405

42. Winkel A, Pedersen O, Ella E, Ismail AM, Colmer TD (2014) Gas film retention and underwater photosynthesis during field submergence off our contrasting rice genotypes. J Exp Bot 65:32253233

43. Xiong QQ, Shen TH, Zhong L, Zhu CL, Peng XS, He XP, Fu JR, Ouyang LJ, Bian JM, Hu LF, Sun XT, Xu J, Zhou HY, He, Chen XR (2019) Comprehensive metabolomic, proteomic and physiological nalyses of grain yield reduction in rice under abrupt rought-flood alternation stress. Physiol Plant 167:564584

44. Yamori W, Hikosaka K, Way DA (2014) Temperature response of photosynthesis in C3, C4, and CAM plants: temperature acclimation and temperature adaptation. Photosynth Res 119:101-117

45. Yang YW, Chen HC, Jen WF, Liu LY, Chang MC (2015) Comparative transcriptome analysis of shoots and roots of tng67 and tcn 1 rice seedlings under cold stress and following subsequent recovery: insights into metabolic pathways, phytohormones, and transcription factors. Plos One 10:e0131391

46. Yu J, Chen L, Xu M, Huang B (2012) Effects of Elevated CO on Physiological Responses of Tall Fescue to Elevated Temperature, Drought Stress, and the Combined Stresses. Crop Sci 52:18481858

47. Zhang RP (2015) The Research Progress of Cold Tolerance Mechanism in Rice. Hubei AgriculturalSciences 54:3844-3848

48. Zhang RP, Ma J, Cai GZ, Sun YJ (2012) Effects of low temperature stress during flowering stage on flowering and seed setting of rice in panxi region, sichuan province. Acta Agronomica Sinica 38:1734-1742

49. Zhu LW, Cao DD, Hu QJ, Guan YJ, Hu WM, Nawaz A, Hu J (2015) Physiological changes and sHSPs genes relative transcription in relation to the acquisition of seed germination during maturation of hybrid rice seed. J Sci Food Agric 96:1764-1771

50. Zia MS, Salim M, Aslam M, Gill MA, Rahmatullah (2008) Effect of low temperature of irrigation water on rice growth and nutrient uptake. J Agron Crop Sci 173:22-31

\section{Tables}

Table 1 MS/MS spectrum database search analysis summary 


\begin{tabular}{|llllll|}
\hline $\begin{array}{l}\text { Total } \\
\text { spectrums }\end{array}$ & $\begin{array}{l}\text { Matched } \\
\text { spectrums }\end{array}$ & Peptides & $\begin{array}{l}\text { Unique } \\
\text { peptides }\end{array}$ & $\begin{array}{l}\text { Identified } \\
\text { proteins }\end{array}$ & $\begin{array}{l}\text { Quantifiable } \\
\text { proteins }\end{array}$ \\
\hline 412489 & 236880 & 31364 & 28934 & 5639 & 4518 \\
\hline
\end{tabular}

Table 2 Enriched KEGG Pathways associated with DEGs and DEPs. 


\begin{tabular}{|c|c|c|c|c|}
\hline \multirow[t]{2}{*}{ pathway name } & \multirow[t]{2}{*}{$\begin{array}{l}\text { Pathway } \\
\text { ID }\end{array}$} & \multicolumn{2}{|l|}{$\begin{array}{l}\text { Number of } \\
\text { molecules }\end{array}$} & \multirow[t]{2}{*}{$P$ value } \\
\hline & & Mapping & All & \\
\hline \multicolumn{5}{|l|}{ KEGG Pathways between LT and CK } \\
\hline Monobactam biosynthesis & osa00261 & 2 & 13 & $\begin{array}{l}5.44 \mathrm{E}- \\
04\end{array}$ \\
\hline Glycine, serine and threonine metabolism & osa00260 & 4 & 26 & $\begin{array}{l}4.69 \mathrm{E}- \\
04\end{array}$ \\
\hline Biosynthesis of secondary metabolites & osa01110 & 10 & 13 & $\begin{array}{l}1.16 \mathrm{E}- \\
04\end{array}$ \\
\hline Pentose phosphate pathway & osa00030 & 2 & 13 & $\begin{array}{l}8.82 \mathrm{E}- \\
03\end{array}$ \\
\hline Biosynthesis of amino acids & osa01230 & 5 & 26 & $\begin{array}{l}8.08 \mathrm{E}- \\
03\end{array}$ \\
\hline Metabolic pathways & osa01100 & 11 & 13 & $\begin{array}{l}2.71 \mathrm{E}- \\
03\end{array}$ \\
\hline Arachidonic acid metabolism & osa00590 & 2 & 26 & $\begin{array}{l}1.96 \mathrm{E}- \\
03\end{array}$ \\
\hline Glycolysis / Gluconeogenesis & osa00010 & 2 & 13 & $\begin{array}{l}4.85 \mathrm{E}- \\
02\end{array}$ \\
\hline Proteasome & osa03050 & 2 & 26 & $\begin{array}{l}4.00 \mathrm{E}- \\
02\end{array}$ \\
\hline $\begin{array}{l}\text { Phenylalanine, tyrosine and tryptophan } \\
\text { biosynthesis }\end{array}$ & osa00400 & 2 & 26 & $\begin{array}{l}2.51 \mathrm{E}- \\
02\end{array}$ \\
\hline Fructose and mannose metabolism & osa00051 & 2 & 13 & $\begin{array}{l}1.44 \mathrm{E}- \\
02\end{array}$ \\
\hline \multicolumn{5}{|l|}{ KEGG Pathways between LTF and CK } \\
\hline Thiamine metabolism & osa00730 & 2 & 14 & $\begin{array}{l}9.73 \mathrm{E}- \\
04\end{array}$ \\
\hline Ribosome biogenesis in eukaryotes & osa03008 & 3 & 20 & $\begin{array}{l}5.79 \mathrm{E}- \\
03\end{array}$ \\
\hline Carotenoid biosynthesis & osa00906 & 2 & 14 & $\begin{array}{l}4.45 \mathrm{E}- \\
03\end{array}$ \\
\hline Biosynthesis of secondary metabolites & osa01110 & 9 & 14 & $\begin{array}{l}2.01 \mathrm{E}- \\
03\end{array}$ \\
\hline Metabolic pathways & osa01100 & 12 & 14 & $\begin{array}{l}1.35 \mathrm{E}- \\
03\end{array}$ \\
\hline Glycine, serine and threonine metabolism & osa00260 & 2 & 20 & $3.28 \mathrm{E}-$ \\
\hline
\end{tabular}


Glycolysis / Gluconeogenesis

osa00010

3

20

$1.67 \mathrm{E}-$

02

KEGG Pathways between LTF and LT

Photosynthesis - antenna proteins

osa00196

9

2.53E-

04

Photosynthesis

osa00195

3

9

$2.12 \mathrm{E}-$

04

The pathway ranking in this table is in order from high to low between LT, LTF and CK. The "mapping" number represents the number of annotated DEGs and DEPs in the pathway, while the "all" number represents the total number of proteins in the pathway. CK: control; LT: low temperature; LTF: Iow temperature flooding.

\section{Figures}
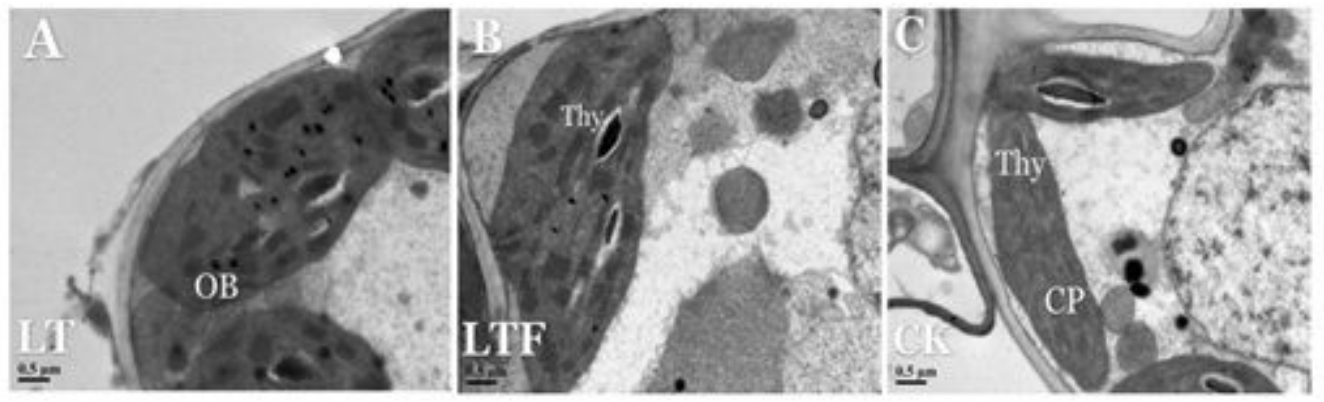

\section{Figure 1}

Transmission electron microscope analysis of the top leaves at rice seedlings stage after low temperature and low temperature flooding stress. CP: chloroplast, Thy: thylakoid lamellae, OB: osmiophilic body. LT: low temperature, LTF: low temperature flooding, CK: control. 

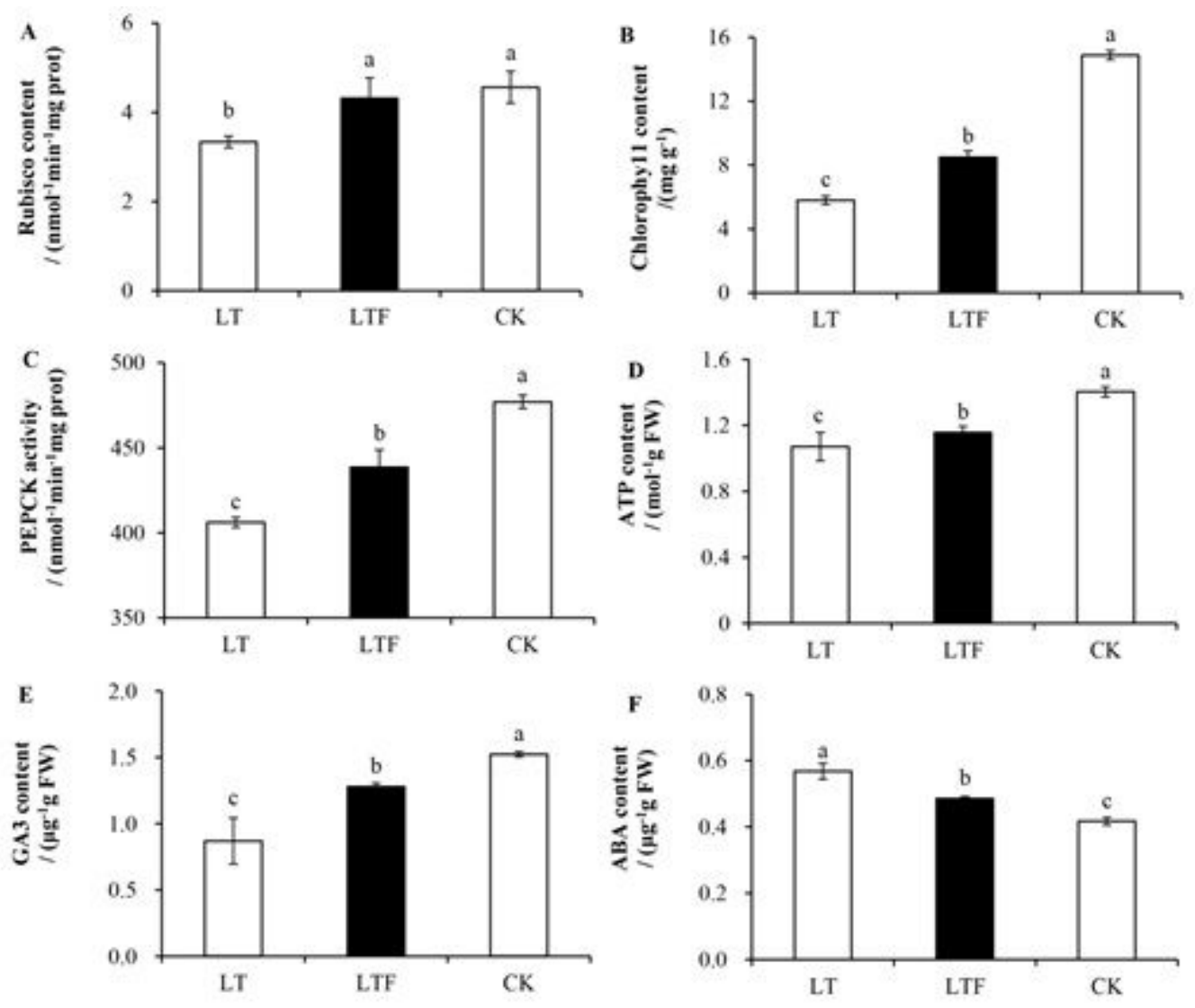

Figure 2

Analysis photosynthate activity and endogenous hormone content. (A) Rubisco content, (B) chlorophyll content, (C) PEPCK activity, (D) ATP content, (E) GA3 content. (F) ABA content. Error bars represent standard deviation $(n=3)$. Data are mean \pm SD. The data were detected by Tukey's honest significant difference (HSD), and different lowercase letters indicated significant differences at $P<0.05$. LT: low temperature, LTF: low temperature flooding, CK: control. 

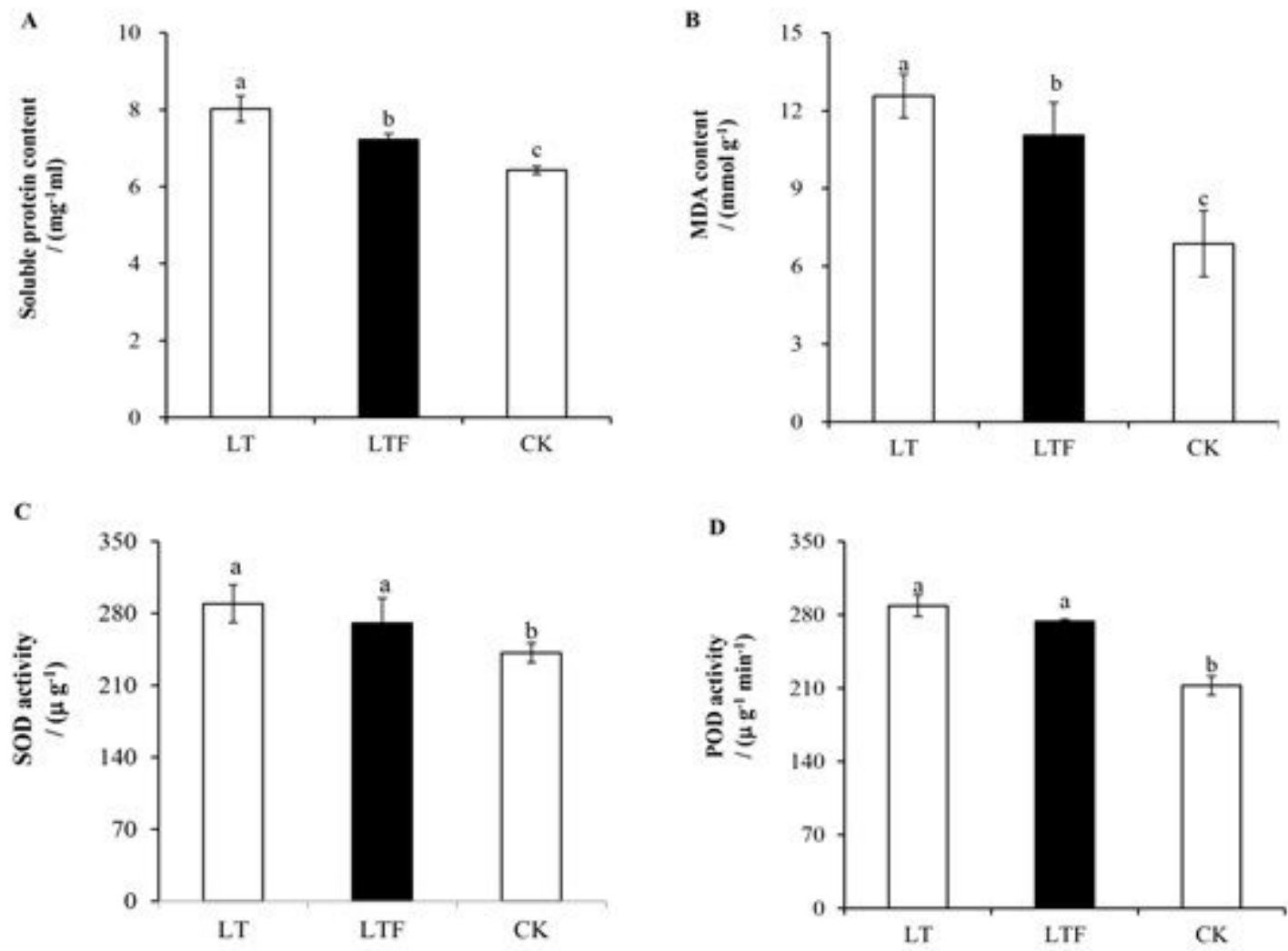

\section{Figure 3}

Analysis of soluble protein content, antioxidase and osmotic regulatory substances. (A) Soluble protein content, (B) MDA content, (C) SOD activity, (D) POD activity. Error bars represent standard deviation $(n=3)$. Data are mean \pm SD. The data were detected by Tukey's honest significant difference (HSD), and different lowercase letters indicated significant differences at $P<0.05$. LT: low temperature, LTF: low temperature flooding, CK: control. 
A

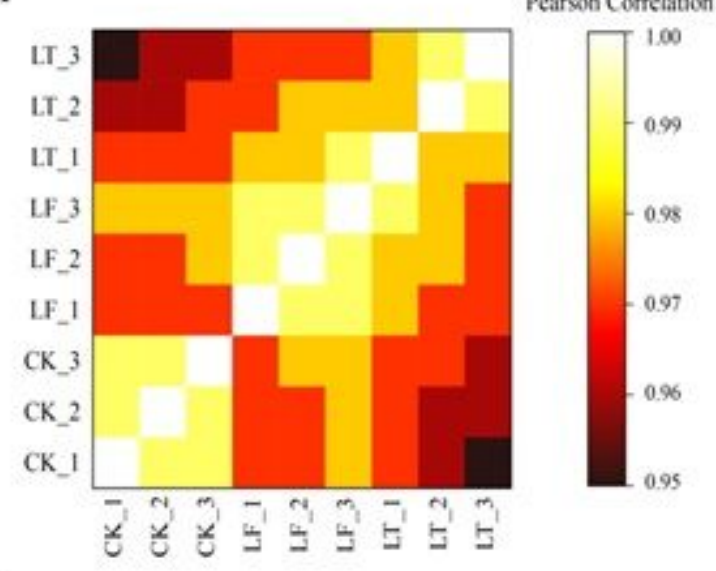

$\mathrm{C}$

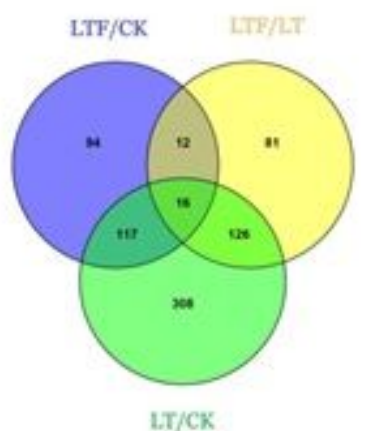

B

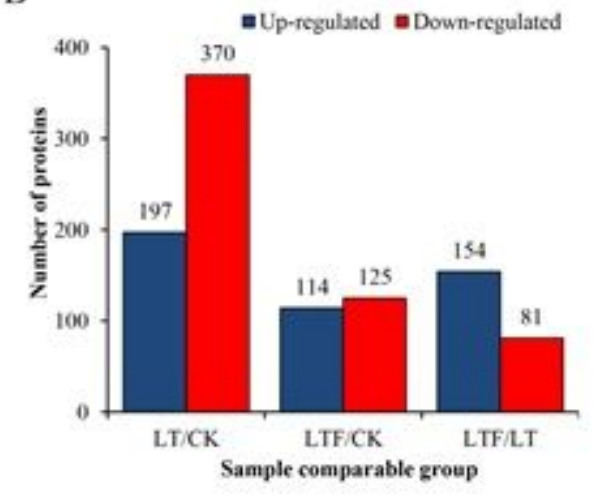

D

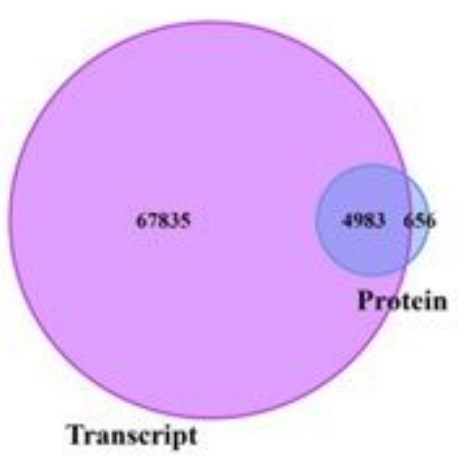

\section{Figure 4}

(A) Pearson correlation coefficient thermograph of protein quantification. A Pearson coefficient closer to -1 indicates a negative correlation, a coefficient closer to 1 indicates a positive correlation and a coefficient closer to 0 indicates no correlation. (B) Summary of up-regulated and down-regulated of DEPs between the treatment groups (LT, LTF) and control group (CK). (C) Venn diagram the DEPs between the treatment groups (LT, LTF) and control group (CK). (D) Comparison of transcriptome and proteome identification. LT: low temperature, LTF: low temperature flooding, CK: control.

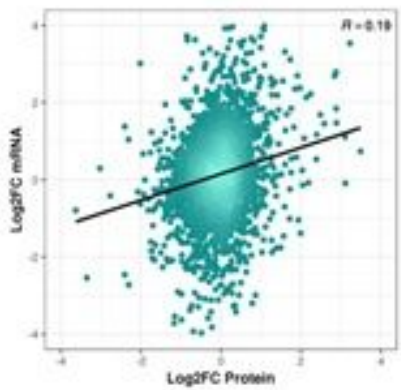

LT/CK

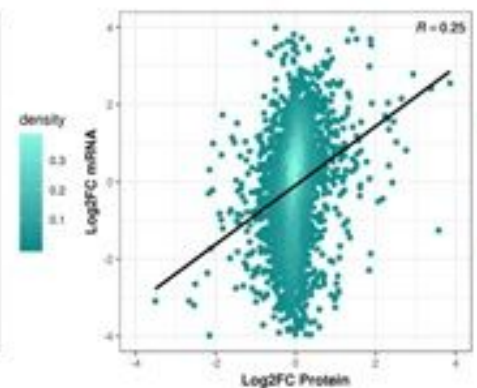

LTF/CK

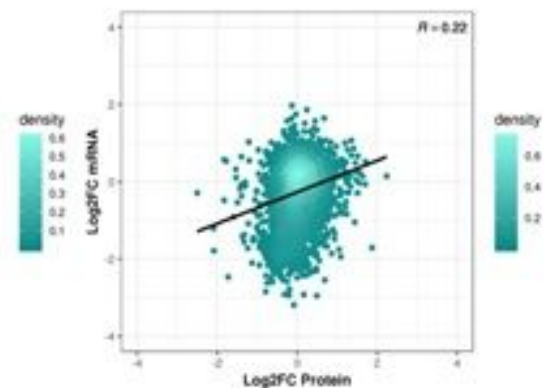

LTF/LT

Figure 5

The transcript and its corresponding protein expression scatter diagram. LT: low temperature, LTF: low temperature flooding, CK: control. 


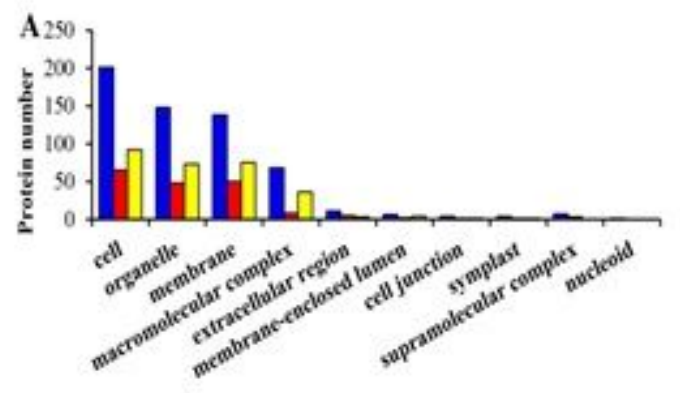

Cellular Component

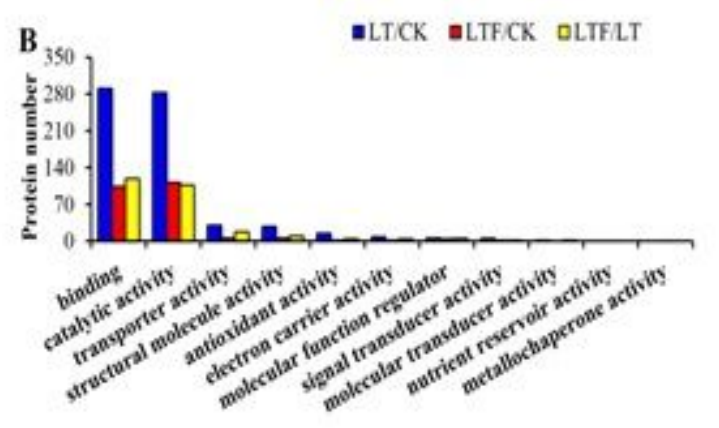

Molecular Function

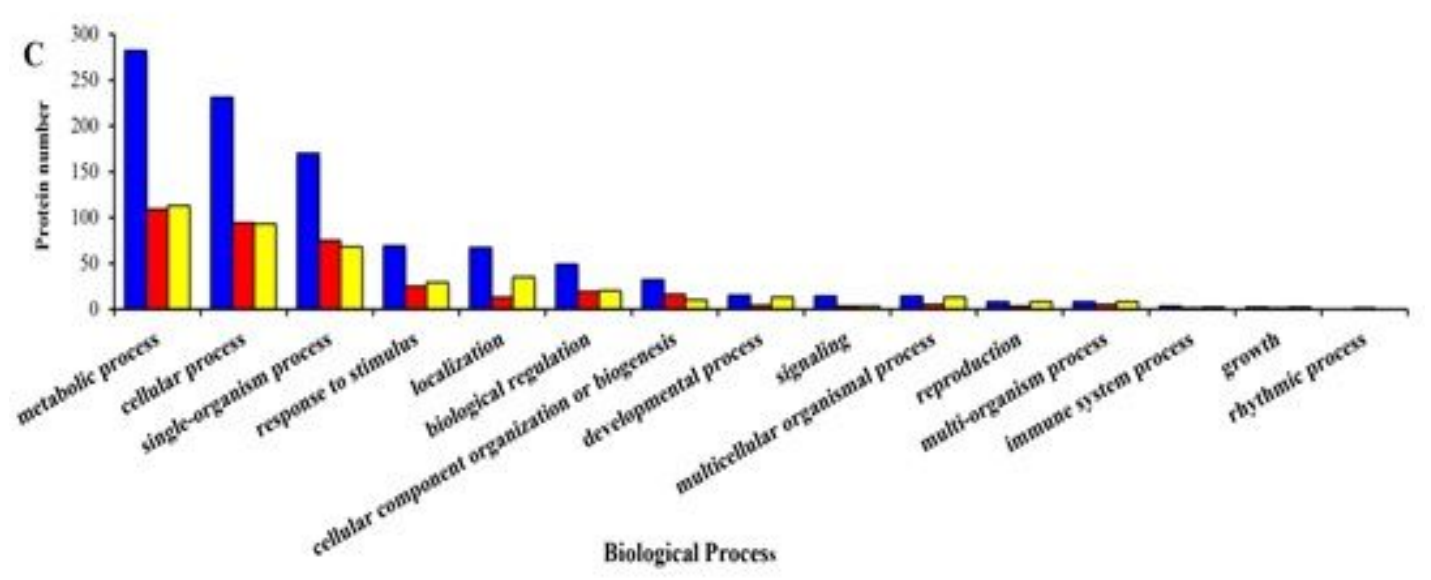

Figure 6

GO enrichment analysis of DEPs between LT, LTF and CK. (A) cellular component, (B) molecular function, (C) biological process. LT: low temperature, LTF: low temperature flooding, CK: control.

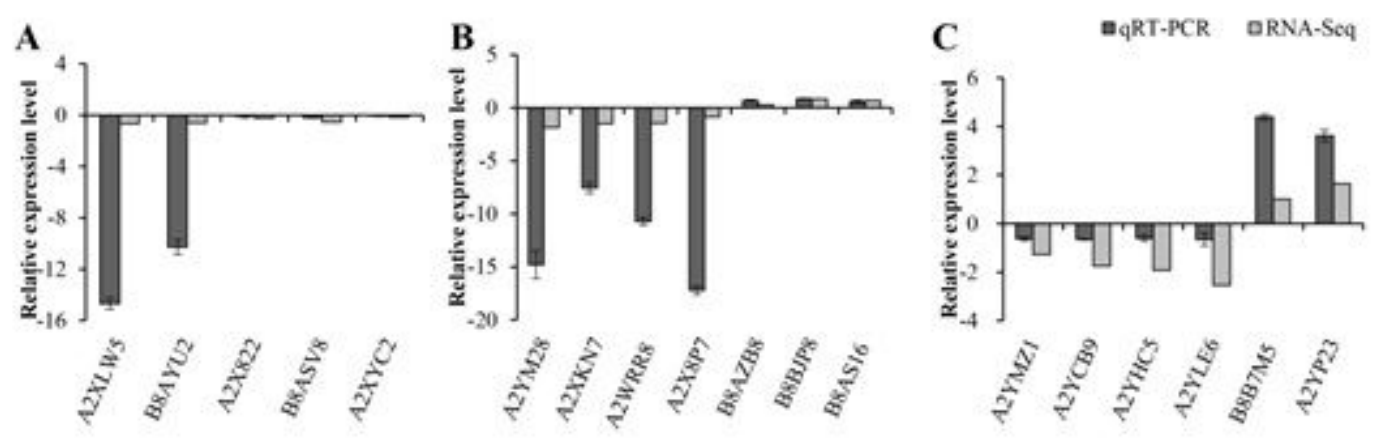

LT/CK

LTF/CK

LTF/LT

Figure 7

Comparison of the expressions of RNA-Seq and qRT-PCR results. A: LT/CK, B: LTF/CK, C: LTF/LT. The transcript levels of the selected genes were each normalized to that of the $18 \mathrm{~s}$ gene. The relative expression of qRT-PCR transcript was calculated according to the standard curve and normalized to $18 \mathrm{~s}$ gene. The calculated data (mean $\pm S D$ ) of three individual $(n=3)$. LT: low temperature, LTF: Iow temperature flooding, CK: control. 


\section{Supplementary Files}

This is a list of supplementary files associated with this preprint. Click to download.

- Coverletter.docx

- DatasetS3.xml

- DatasetS2.xml

- DatasetS1.xml

- TableSupplements.docx

- FigureSupplements.docx 